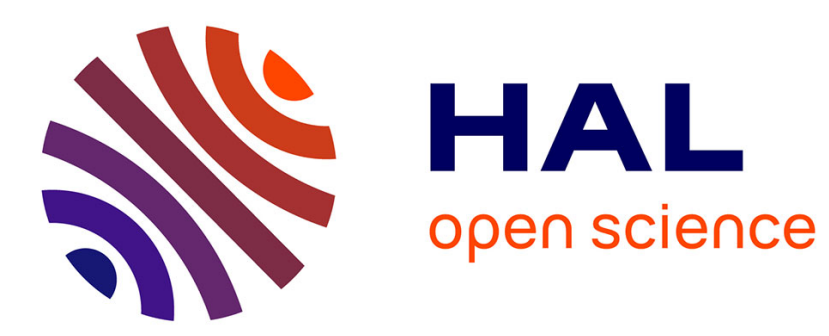

\title{
Incentives for Partial Acquisitions and Real Market Concentration
}

\author{
Patricia Charléty, Marie-Cécile Fagart, Saïd Souam
}

\section{To cite this version:}

Patricia Charléty, Marie-Cécile Fagart, Saïd Souam. Incentives for Partial Acquisitions and Real Market Concentration. 2007. hal-00143911

\section{HAL Id: hal-00143911 https://hal.science/hal-00143911}

Preprint submitted on 5 May 2007

HAL is a multi-disciplinary open access archive for the deposit and dissemination of scientific research documents, whether they are published or not. The documents may come from teaching and research institutions in France or abroad, or from public or private research centers.
L'archive ouverte pluridisciplinaire HAL, est destinée au dépôt et à la diffusion de documents scientifiques de niveau recherche, publiés ou non, émanant des établissements d'enseignement et de recherche français ou étrangers, des laboratoires publics ou privés. 


\title{
Incentives for Partial Acquisitions and Real Market Concentration
}

\author{
Patricia Charléty* Marie-Cécile Fagart ${ }^{\dagger}$ and Saïd Souam ${ }^{\ddagger}$
}

February 15, 2007

\begin{abstract}
We analyze the incentives of a controlling shareholder of a firm to acquire, directly or indirectly through his firm, shares in a competitor. We charaterize the conditions under which these partial acquisitions are profitable for this dominant shareholder as well as the equilibrium toehold and its nature: controlling or silent. We find that while this shareholder gains, the acquisition is detrimental to minority shareholders of his firm, or of the target, or even of both. We show that the incentives are enhanced if the dominant shareholder initially holds silent stakes in rivals while controlling interests may discourage them. Moreover, we find that partial acquisitions always lead to a decrease in the joint profit of the two firms involved, and an increase in competitors's profits as the market becomes less competitive.

Keywords: horizontal partial acquisitions, real market concentration, dominant shareholder, minority shareholders, silent interests.

JEL classification: D23, D43, G32, G34.

*ESSEC Business School, Départements d'Economie et de Finance, PO Box 105, 95021 Cergy-Pontoise Cedex, France. email: charlety@essec.fr

†University of Rouen. email: mariececile.fagart@wanadoo.fr

$\ddagger$ Corresponding author. University of Paris-Nord (CEPN) and CREST-Laboratoire d'Economie Industrielle, 28 rue des Saints Pères 75007 Paris, France. souam@ensae.fr
\end{abstract}




\section{Introduction}

After acquiring a $20 \%$ stake in Havas in 2005, a French advertising and media conglomerate, Vincent Bolloré built up a holding of $29 \%$ in Aegis equity capital, a British direct competitor in the media industry. As a minority but dominant shareholder of Havas, the French entrepreneur is the Chairman and CEO of the company, and the majority of the board is affiliated to him. By contrast, although Bollore is also the dominant shareholder of Aegis, he has no representative in the board and until now did not make any offer to gain control of the company. ${ }^{1}$ Bolloré actually sought representation in the board of Aegis but the resolution did not pass. Aegis' board recommended to vote against the resolution arguing that "Groupe Bolloré's interests are unlikely to coincide with the interests of Aegis shareholders as a whole". Although Bolloré has no direct influence on Aegis' management, he decided to keep his stake in the company. This example is by no means unique. As a result of partial acquisitions, in many continental european countries shareholding power is highly concentrated in the hand of large shareholders (Becht and Röell, 1999), who sometimes are also competitors. Even in the United States, the presence of a large voting block is not uncommon in listed companies (Becht and Mayer, 2002). As Dahya, Dimitrov and Mc Connell (2006) document, on average $47.1 \%$ of the board is affiliated to the dominant shareholder, and $40.7 \%$ of the votes are under his control. ${ }^{2}$ Depending on the size of the toehold, but also on the legal environment, the existence of multiple voting rights, ...the dominant shareholder may control the firm (as Bolloré in Havas), in particular when the remaining equity is in the hand of small shareholders as is often the case.

Although partial acquisitions are common in corporate life ${ }^{3}$, they received relatively little attention from economists. Especially, the motivation for acquiring a substantial but noncontrolling share of equity, what we will call a silent acquisition (as Bolloré's in Aegis), is not

\footnotetext{
${ }^{1}$ With $30 \%$ equity, he would have to launch a tender offer under the british law.

${ }^{2}$ The dominant shareholder is defined as holding at least $10 \%$ of the equity capital; the authors conclude that in countries with a better legal protection of minority shareholders, broadly Common Law countries, the power of the dominant shareholder is weaker than in countries with less protection, typically Civil Law countries.

${ }^{3}$ For example, during the period 2000-2003 there are around 700 crossings of thresholds of at least 5\% of equity involving a listed company in France each year compared with around 30 tender offers and even fewer mergers.
} 
clear. Other questions remain largely unanswered: How is the optimal toehold in the target determined? How do existing toeholds affect the subsequent acquisition policy? What is the impact of partial acquisitions on the individual and the overall profit of the firms involved in the transaction, and their competitors? In this article, we address these questions in the particular case of block trades between large shareholders of firms from the same industry. Our work is threrefore related to both the Industrial Organization as well as the Corporate Governance literature.

The first economic contributions on the topic have emphasized the fact that horizontal partial ownerships, even small and silent ones, may lessen competition because competitors internalize the negative externality they impose to each other while being aggressive in a market. Bresnahan and Salop (1986), and Reynolds and Snapp (1986) have shown this result in the case of joint-ventures. Flath (1991) shows that a non controlling partial ownership of a firm in another one has typically two effects: a direct effect which induces the acquirer to sacrifice some of its own revenue in order to see its stake in the other firm better valued; the second effect is a strategic one and is due to the rival's response to this toehold. The direct effect is always negative while the second one depends on the type of competition. Within a Cournot context, it is also negative which makes a partial ownership not profitable. Conversely, in a Bertrand setting the strategic effect is positive. The non controlling share could then be profitable for the owner. ${ }^{4}$

In a vertical framework, Flath (1989) shows that symmetric vertical ownerships in a Cournot model may enhance the mark-up of firms and could then be detrimental to competition, contrary to the result of vertical integration (elimination of the double margin phenomena). Dasgupta and Tao (2000) showed that a downstream share in an upstream

\footnotetext{
${ }^{4}$ Basically, this is the same argument than the one in Salant, Switzer and Reynolds (1983) which shows the unprofitability of horizontal mergers. This extreme result is due to the linearity of the cost of production and the type of competition. Much less stringent conditions under which merging firms benefit from the market power they create can be found in different contributions including Perry and Porter (1985) or Deneckere and Davidson (1985). Reitman (1994) has extended this result to partial ownership arrangements: if the industry's overall profit increases following a partial acquisition, the beneficiaries are the rival companies which benefit from a positive externality (increase in prices) whereas the firms involved in the transaction lose, which removes any incentive. Similarly, Farrell and Shapiro (1990) show that a marginal increase in an initial toehold is profitable only when a cost reduction compensates the negative effect of a less aggressive behavior of the companies involved (production restriction) and may be socially desirable in that case.
} 
firm could be helpful to eliminate the vertical opportunism due to specific investments.

Another strand of the economic literature studies toeholds as a facilitating device for collusion. Gilo, Moshe and Spiegel (2006) establish necessary and sufficient conditions for partial cross ownership arrangements to facilitate tacit collusion. ${ }^{5}$ Different empirical studies have shown the potential negative impact of partial ownership in different sectors: as a collusion facilitating device in Parker and Röller (1997) in the U.S. mobile telephone industry, Alley (1997) in the U.S. Automobile Industry, or as way to re-establish market power in Dietzenbacher, Smid and Volkerink (2000) for the Dutch Financial sector, Amunden and Bergman (2002) in the Nordic Power Market, and Campos and Vega (2003) in the Spanish Electricity Sector.

Whereas the IO literature examines the competitive effects of toeholds in the industry, the the Corporate Governance literature focuses on their consequences for the different groups of shareholders in a company. It is mainly concerned with the role of large and possibly controlling shareholders in defending or expropriating the minority.

The positive role of toeholds in the context of the market for corporate control has been emphasized since the seminal paper of Shleifer and Vishny (1986) who showed that the presence of a large shareholder facilitates value enhancing takeovers. Following their analysis, several authors examined explicitly the strategy of acquisition of a stake in the target before launching a tender offer. For example, Chowdhry and Jegadeesh (1994) predict that the higher the target valuation by the acquirer, the higher the toehold, and the higher the price paid for the remaining shares. Bris (2002) shows that in some cases, because the price paid increases with the toehold, it may be optimal to acquire no stake in the target before launching the tender offer. This result is consistent with the empirical findings of Betton and Eckbo (2000) or Becher and Swicher (2002) who find that very often the acquirer holds no previous share in the target. The Corporate Governance literature also extensively analyzed the monitoring role of a large/controlling shareholder: whereas small shareholders rationally remain passive, large shareholders incur the cost of acquiring information about the firm and its environment and of controlling the management, in order to increase the value of the shares they hold. Minority shareholders therefore gain from the presence of blocks. ${ }^{6}$

\footnotetext{
${ }^{5}$ Malueg (1992) however provides an example where an increase in the symmetric partial cross ownership does not facilitate tacite collusion.

${ }^{6}$ The literature on this topic has flourished over the past decade; see for example Burkart, Gromb and
} 
However the presence of large shareholders may also create problems, as they may pursue "private interests" at the expense of minority shareholders. ${ }^{7}$ In a model where controlling shareholders extract private benefits, Bebchuk (1994) shows that value decreasing transfers of controlling blocks may occur, as well as value increasing ones be prevented. ${ }^{8}$ Burkart, Gromb and Panunzi (2000) also showed that private negotiation of controlling blocks enables more extraction of private benefits by large shareholders. Barclay and Holderness (1989, 1991, 1992) and Barclay, Holderness and Sheehan (2001) find that blocks of $5 \%$ or more of equity are negotiated at a price substantially above ${ }^{9}$ the exchange price and attribute this premium to the existence of private benefits to controlling shareholders. More recently, Johnson, La Porta, Lopez-de Silanes and Shleifer (2000) reported several legal cases in Belgium, France, Germany and Italy where resources have been transfered out of a company to its controlling shareholders (what the authors have called "tunnelling").

Our article borrows from both the IO and the Corporate Governance literature. It examines the strategic interaction of production and financial decisions within an integrated model of partial acquisitions where the potential benefits, "private" or "public" of the transaction are endogeneously determined in the real sector. ${ }^{10}$ More precisely, we study the incentives for horizontal partial acquisitions, controlling or silent (i.e. without transfer of control or power of any kind) in an oligopolistic industry producing a homogeneous good in the absence of synergies. We assume that the strategic decision to acquire equity in a rival belongs to the dominant controlling shareholder of one company in the industry who may already hold outside toeholds. We find that, maximizing his own wealth, this shareholder may engage Panunzi (1997) or Bolton and Von Thadden (1998) for a theoretical approach, and La Porta, Lopez-Silanes, Shleifer and Vishny (2002) for a discussion of the role of the large shareholder.

${ }^{7}$ The fact that, within groups of firms, some categories of shareholders may be favored at the expense of others has long been acknowledged by the finance literature. Indeed, the dilution of minority shareholders' wealth following a tender offer is actually a solution to the free-rider problem in Grosman and Hart (1980, 1981).

${ }^{8}$ Similarly, Kahan (1993) examines cases where a dominant shareholder deriving private benefits from the control of firms engages in transactions at the expense of other shareholders (public value decreasing transfers of control).

${ }^{9}$ For example, the estimated premium is $20 \%$ on average in Barclay and Holderness (1989).

${ }^{10}$ The linkage between productive and financial decisions is an important feature of our model. As for Brander and Lewis (1986) in another context (the choice of debt), the functioning of financial markets has an important impact on the economic performance of the real sector. 
in privately profitable negotiations with the controlling shareholder of a rival. On the contrary, the acquisition hurts either the minority shareholders of his firm in the case where his controlling toehold is relatively small, or those of the target if the reverse is true, and may even be detrimental to both groups of shareholders when the acquirer initially holds a relatively large overall silent stake in the industry outside the two firms. Overall the joined profit of the companies involved and the consumers' surplus always decrease following the transaction.

In our setting, the negotiating shareholders correctly anticipate the level of the profits of all firms in the industry following the acquisition. As it depends on the level of the toehold and its nature (controlling or silent), so will the price paid for the acquired shares. This interaction explains how the optimal level of the toehold is determined (and the unit price) and why, in some cases, it is preferable to acquire only a silent stake. The ownership structure of the bidder and the target thus turns out to be a key variable: the higher the toehold of the dominant shareholder in the company he initially controls, the better the protection of minority shareholders of this firm. Another finding is that initial silent toeholds in rivals increase the incentive to further make partial acquisitions. This is due to higher value of these outside interests following the price increase in the whole industry as competition lessens. On the other hand, the impact of initial controlling toeholds turns out to be ambiguous. ${ }^{11}$

Accounting for the effects in the industry is therefore essential for a good understanding of the acquisition process and the consequences for shareholders' wealth. Integrating productive and financial decisions reintroduces an incentive for horizontal equity acquisitions, which, in our setting, always destroy value from the viewpoint of the firms involved in the transaction and are inefficient from a social point of view as they lead to higher prices in the industry. The results also emphasize the importance of initial toeholds, in particular silent ones, in companies other than the target for the future acquisition policy; it predicts that partial acquisitions should come in chain and result in a "creeping monopolization" of the industry. Our paper therefore implies that not only financial authorities who traditionally aim at protecting minority shareholders' interst, but also competition authorities should consider partial acquisitions, even silent ones, with scrutinity. From this perspective, it also relates

\footnotetext{
${ }^{11}$ Interestingly, although the importance of initial toeholds in the target has been emphasized in the finance literature (see for example Högfeldt and Högholm, 2000, Bulow, Huang and Klemperer, 1999, or Singh, 1998), the role of toeholds in rivals has not, to our knowledge, been examined.
} 
closely to a recent antitrust literature. Indeed, the treatment of partial ownership interests is an important issue for antitrust. However, it is not clear whether they should be compared to mergers or to naked price fixing. ${ }^{12}$ Partial ownership interests and joint ventures have become more important in telecommunications and high technology industries. ${ }^{13}$ O'Brien and Salop (2000) and Gilo (2000) argue that even passive investment in the competitors could have important anticompetitive effects and should be analyzed with more scrutinity even though the U.S. antitrust agencies (FTC and DOJ) have recently investigated and challenged some minority equity interests by firms in their competitors. ${ }^{14}$

Our paper is organized as follows. The model is presented in section 2. In section 3, we study the equilibrium in the good market for given toeholds. In section 4 , we solve the acquisition game under two different bidding possibilities, analyze the conditions (quantities and price) of the transactions and their wealth consequences for shareholders.

\section{The model}

We consider an oligopolistic market with $n$ firms producing a homogeneous good. The demand is $P(X)=1-X$ where $X$ represents the total quantity produced in the industry and $P$ the corresponding price. Each company $i=1, \ldots, n$ produces $X_{i}$ and $X=\sum_{j=1}^{n} X_{j}$. The marginal cost is supposed to be constant and is normalized to zero for all firms. Under these assumptions, profits are $\Pi_{i}=P(X) X_{i}$ for all $i$.

Total equity capital is normalized to 1 for all firms. Each company is controlled by a dominant shareholder. The dominant shareholder chooses the production of the firm(s) he controls (possibly with less than $50 \%$ of the shares) and maximizes his own wealth. Initially, the dominant shareholder of any company $i$ holds no equity in other companies $j \neq i$ in this market, except for A, the dominant shareholder of firm 1, who already owns stakes $\alpha_{j}$ in firms $j>2$ in addition to his controlling share $\left.\left.\alpha_{1} \in\right] 0,1\right]$ in firm 1 . These toeholds $\alpha_{j}$ held in competitors may be controlling or non controlling ("silent"). In the case of a controlling share $\alpha_{k}$, A initially chooses the production level $X_{k}$ of firm $k$ controlled in addition to $X_{1}$.

\footnotetext{
${ }^{12}$ See for example the case of British American Tobacco and Reynolds vs. European Commission 142 and 156-84, R, 4487. The European Court of Justice has investigated a possible violation of article 81 of the Treaty.

${ }^{13}$ O'Brien and Salop (2000) mention many examples of such partial interests.

${ }^{14}$ See Dubrow (2001) for an opposite view.
} 
Controlling shareholders compete à la Cournot.

We look at the case where shareholder A (and only him by assumption) may buy, directly or indirectly, all or part of the block of shares $\left.\left.\beta_{2}\left(\beta_{2} \in\right] 0,1\right]\right)$ initially held by $\mathrm{B}$, the dominant shareholder of firm 2. The remaining equity of 2 is supposed to be widely held. In the case of an indirect acquisition, firm 1 rather than A buys the shares, still under A's initiative. After this acquisition, he may therefore control company B if he (or firm 1) becomes the largest shareholder. In this case, he decides also on the production level $X_{2}$. If after the acquisition of stock by A (or firm 1), B remains the largest shareholder in firm 2, B keeps controlling $X_{2}$. Let $\left.\left.\alpha_{2} \in\right] 0,1\right]$ be the share of equity acquired in firm 2 by A directly or indirectly from $\mathrm{B}$; in the case of an indirect acquisition, $\left.\left.\widehat{\alpha}_{2} \in\right] 0,1\right]$ represents the amount acquired by firm $1 ; \alpha_{2} p$ (resp. $\widehat{\alpha}_{2} p$ ) is the total amount paid for the transaction by A (resp. by firm 1). After the acquisition, the wealth of shareholder $\mathrm{A}$ is therefore $\alpha_{1} \Pi_{1}+\alpha_{2}\left(\Pi_{2}-p\right)+\sum_{j>2} \alpha_{j} \Pi_{j}{ }^{15}$ The wealth of B becomes $\left(\beta_{2}-\alpha_{2}\right) \Pi_{2}+\alpha_{2} p$ after a direct acquisition, or $\left(\beta_{2}-\widehat{\alpha}_{2}\right) \Pi_{2}+\widehat{\alpha}_{2} p$ after an indirect one. The other shareholders' wealth solely depends on the profits of their company. The objective of shareholders is to maximize the value of their financial wealth.

Although most IO literature assumes that firms maximize profits, the assumption that a dominant shareholder controls the firm in his own interest is common in the finance literature. In practice, this can be interpreted as appointing the board. In a recent study, Dahya, Dimitrov and Mc Connell (2006) analyze the composition of the board and performance of firms with a dominant shareholder in 22 countries. They document that on average $47 \%$ of the board is affiliated with the dominant shareholder who holds on average $33 \%$ of cash flow rights. Even in the United Kingdom where dominant shareholders are less frequent and hold relatively fewer shares (20,3\% of cash flow rights on average), the percentage of affiliated directors is on average $42 \%$. In some cases though, the board is only composed of directors independent of the large shareholder, while in others $100 \%$ of the board is affiliated with the dominant shareholder. The fact that some boards are completely independent does not contradict the hypothesis that the large shareholder controls the firm. If the dominant shareholder's wealth is closely related to the value of the controlled company, his personal objective is to maximize profits. The best way to achieve this goal might be to appoint an

\footnotetext{
${ }^{15}$ In the case of an indirect acquisition, A's final wealth is: $\alpha_{1}\left[\Pi_{1}+\widehat{\alpha}_{2}\left(\Pi_{2}-p\right)\right]+\sum_{j>2} \alpha_{j} \Pi_{j}=\alpha_{1} \Pi_{1}+$ $\alpha_{2}\left(\Pi_{2}-p\right)+\sum_{j>2} \alpha_{j} \Pi_{j}$ where share $\alpha_{2}$ of $\mathrm{A}$ in 2 is $\alpha_{1} \widehat{\alpha}_{2}$.
} 
independent board. ${ }^{16}$ On the other hand, if the dominant shareholder diverts private benefits at the expense of minority shareholders, he is more likely to appoint directors affiliated to him.

In our model, the controlling shareholders of all firms but 1 have no outside toehold. Their interest therefore coïncides with the interest of minority shareholders and their objective is to maximize the firm's profits. This is different for A, the dominant shareholder of firm 1, who has toeholds (controlling or silent) in competitors. The objective is to analyze how these initial toeholds affect the incentives to make further acquisitions, controlling or silent, and evaluate their consequences for blockholders, minority shareholders and consumers.

The timing of the global game is the following: A (or firm 1) acquires equity in 2 in the first stage of the game, determining $\alpha_{2}$ and $p$; in the second stage, dominant shareholders choose simultaneously the production level of the firm(s) they control given $\alpha_{2}$. Next section examines the Nash equilibrium of this production game. The first stage of the game, the acquisition of equity by $\mathrm{A}$ in firm 2, is presented in section 4 where we analyze the existence of bidding Nash equilibria.

\section{The equilibrium in the real sector}

In this section, we analyze the equilibrium in the real sector after the bidding game has taken place. In the case of a successful acquisition, A has acquired (directly or indirectly) a toehold $\alpha_{2}$ in firm 2 (in addition to the shares $\alpha_{j}$ he already owns in firms $j>2$ ) that may or may not give him the control of this firm. At this stage the amount $\alpha_{2} p$ paid by A to shareholder B is a sunk cost and therefore does not influence the production decisions of any firm. The toeholds $\alpha_{2}$ and $\alpha_{j}$ affect the production decisions of $\mathrm{A}$ in two ways. When setting the output of the firm(s) he controls (at least firm 1), A takes into account the direct effect of the output level of the controlled firm(s) on its (their) own profits, but also the indirect effect on the profits of the companies in which he holds an interest, silent or controlling. Let $\mathcal{C}$ represent the set of firms (the "core" group) controlled by $\mathrm{A}$, and $\mathcal{G}$ the set of firms in which A holds a stake, controlling or not (the "greater" group). The number of firms in which $\mathrm{A}$ has a silent stake is denoted $n_{s}$ and $n_{c}$ is the number of firms controlled by $\mathrm{A}$.

\footnotetext{
${ }^{16}$ Dahya, Dimitrov and Mc Connell (2006) find a positive relation between the fraction of independent directors and the firm value.
} 
Thus we have a Cournot game with $\left(n-n_{c}\right)$ dominant shareholders choosing the output of the firm they control in order to maximize its profits, and A choosing the production of the $n_{c}$ firms controlled in order to maximize his wealth $\sum_{i=1}^{n} \alpha_{i} \Pi_{i}$.

Obviously, the quantities produced in equilibrium depend on $n_{c}$. It turns out that they also depend on the ratio of the sum of the silent interests held by $\mathrm{A}$ in his rivals denoted $\alpha_{s}$ to his highest controlling stake denoted $\alpha_{c}$. Let $\rho$ represent this ratio: ${ }^{17}$

$$
\rho=\frac{\alpha_{s}}{\alpha_{c}} \text { with } \alpha_{s}=\sum_{i \notin \mathcal{C}} \alpha_{i} \text { and } \alpha_{c}=\operatorname{Max}\left\{\alpha_{i}, i \in \mathcal{C}\right\}
$$

The following proposition gives the quantities and the profits of the firms in equilibrium.

Proposition 1 Equilibrium quantities and profits are given by the following equations (1)(4). Among the $n_{c}$ firms controlled by A, only the firm with the highest weight may have positive production and profits $\left(X_{i}^{*}=\Pi_{i}^{*}=0\right.$ for $i \in \mathcal{C}$ and $\left.\alpha_{i}<\alpha_{c}\right)$.

$$
\begin{aligned}
X_{j}^{*}\left(\alpha_{1}, \alpha_{2}, \ldots, \alpha_{n}\right) & =\frac{1}{n-n_{c}+1+\max (1-\rho, 0)} \text { for } j \notin \mathcal{C} \\
\sum_{i \in \mathcal{C}} X_{i}^{*}\left(\alpha_{1}, \alpha_{2}, \ldots, \alpha_{n}\right) & =\frac{\max (1-\rho, 0)}{n-n_{c}+1+\max (1-\rho, 0)} \\
\Pi_{j}^{*}\left(\alpha_{1}, \alpha_{2}, \ldots, \alpha_{n}\right) & =\frac{1}{\left[n-n_{c}+1+\max (1-\rho, 0)\right]^{2}} \text { for } j \notin \mathcal{C} \\
\sum_{i \in \mathcal{C}} \Pi_{i}^{*}\left(\alpha_{1}, \alpha_{2}, \ldots, \alpha_{n}\right) & =\frac{\max (1-\rho, 0)}{\left[n-n_{c}+1+\max (1-\rho, 0)\right]^{2}} .
\end{aligned}
$$

All the proofs are given in the appendix.

\subsection{The different effects at play}

Proposition 1 reflects the restructuring that A operates within the group $\mathcal{C}$ of the $n_{c}$ firms he controls given the reaction of his rivals, including the firms in which he has silent interests (belonging to $\mathcal{G}$ but not in $\mathcal{C}$ ), in equilibrium. Different mechanisms or "effects" are actually at play.

\section{The "favorite" effect}

\footnotetext{
${ }^{17}$ For instance, when A holds shares in only three firms, say 1,2 and 3 , and A controls firm 1 only, $\mathcal{C}=\{1\}$, $\alpha_{s}=\alpha_{2}+\alpha_{3}, \alpha_{c}=\alpha_{1}$ and $\rho=\frac{\alpha_{2}+\alpha_{3}}{\alpha_{1}}$; when A controls two firms, say 1 and $2, \mathcal{C}=\{1,2\}, \alpha_{s}=\alpha_{3}$, $\alpha_{c}=\operatorname{Max}\left(\alpha_{1}, \alpha_{2}\right)$ and $\rho=\frac{\alpha_{3}}{\operatorname{Max}\left(\alpha_{1}, \alpha_{2}\right)}$; when A controls all three firms, $\mathcal{C}=\{1,2,3\}, \alpha_{s}=0$ and $\rho=0$.
} 
Proposition 1 implies $X_{i}^{*}=\Pi_{i}^{*}=0$ for $i \in \mathcal{C}$ and $\alpha_{i}<\alpha_{c}$. This means that among the $n_{c}$ firms controlled by A, only the firm which has the highest weight $\left(\alpha_{c}\right)$ in his portfolio (say firm 1) possibly remains active. A chooses to stop the production of all other controlled companies. In other words, A favors the controlled firm in which he has the highest stake. This "favorite" effect obviously harms shareholders of the other controlled firms. Controlling acquisitions are in this model formally equivalent to a complete merger of the $n_{c}$ firms into at most one company. Indeed, only in the case where the highest controlling stake (say $\alpha_{1}$ ) is greater than the sum of A's silent interests $\alpha_{s}$ does firm 1 remains active.

\section{The "Hara Kiri" effect}

When the highest controlling stake $\alpha_{c}$ (say $\alpha_{1}$ ) is lower than the sum of the silent interests in competitors $\alpha_{s}$, i.e. $\rho \geq 1$, A also shuts down the corresponding controlled firm (say 1) in order to concentrate the production and profit where his stake is the highest: all the controlled production units are closed. This "Hara Kiri" effect benefits shareholders of all rivals to the detriment of those of all controlled companies, in particular firm 1.

The extreme results for the favorite and Hara Kiri effects are due to the linearity of the model (constant marginal costs) and to the hypothesis of homogenous products. Less radical effects would be obtained in other frameworks (quadratic costs or product differentiation). The key point is that some controlled firms will be downsized, through reallocations of production between firms, depending on the relative stakes of the dominant shareholder. The minority shareholders of these downsized firms are harmed. This kind of restructuring of firms is rather frequent in practice.

\section{The "silent" effect}

Conversely, when his highest controlling toehold in a firm (say $\alpha_{1}$ ) is greater than the total of silent stakes in rivals $\alpha_{s}$ (i.e. $\rho<1$ ), A would like to concentrate the production in the controlled firm and shut down the firms in which he has a silent stake but, being a minority shareholder, does not have the power to do so. On the contrary, A internalizes the negative consequences of the production of the active controlled company on the value of his silent interests, and therefore restricts its output to limit the negative externalities on the value of his outside interests ( "silent" effect).

Rivals (including competitors in which A has a stake) react to this restriction of the 
controlled firm (say 1) output by increasing their production to take advantage of the price increase. The higher the value of $\rho$, the higher the restriction of 1's output, the stronger its competitors' reaction and the higher their profits.

This discussion sheds some light on the crucial role played by $\rho$ (the ratio of the global silent interests held by A in his rivals to his highest controlling stake) in equilibrium. Actually, keeping the production of non controlled firms constant (out of equilibrium), toeholds always make shareholder A (i.e. the group $\mathcal{C}$ of firms under his control) less "aggressive": he restricts the global production of the controlled group $\mathcal{C}$ to increase its profit. For given production levels of non controlled firms, the global profit of group $\mathcal{C}$ would increase. But as mentioned above, controlling shareholders of rivals outside of $\mathcal{C}$ do not remain passive and react to the restriction of the output by $\mathcal{C}$ and the higher resulting price. This is the strategic effect underlined by Fudenberg and Tirole (1984). We are in their classical case of strategic substitutes. In the Cournot model, when a firm is less aggressive, other firms respond by more aggressiveness.

Figure $^{18} 1$ (resp. ${ }^{19}$ 2) illustrates the aggregate best-response curve of firms in group $\mathcal{C}$ (resp. in the "greater" group $\mathcal{G}$ ), and the aggregate best response curves of their competitors. The Cournot equilibrium lies at the intersection of the best-response curves. In either case, when $\rho$ increases, the best-response curve of the group $(\mathcal{C}$ or $\mathcal{G})$ moves to the left (from the Cournot best response curve for $\rho=0$ at one extreme to that of the merged entity of the basic Cournot model when $\rho>1$ at the other extreme). Thus both groups $\mathcal{C}$ and $\mathcal{G}$ become less aggressive as $\rho$ increases.

\section{Insert Figure 1 and Figure 2.}

\footnotetext{
${ }^{18}$ Figure 1 is built as follows. Suppose the production of group $\mathcal{C}, X$ is given. The best response of a firm $i$ satisfies $X_{i}=1-X-\sum_{j \notin \mathcal{C}} X_{j}$. For given $X$, one can calculate the game equilibrium among the other firms, i.e. the response of all the other firms to the choice of $X$ by shareholder A. This response is given by: $Y=\sum_{j \notin \mathcal{C}} X_{j}=\frac{n-n_{c}}{n-n_{c}+1}(1-X)$. The best response of group $\mathcal{C}$ controlled by $\mathrm{A}$ is then: $2 X=\operatorname{Max}\left(0,1-\frac{n-n_{c}+\rho}{n-n_{c}} Y\right)$.

${ }^{19}$ Using the same method, we can determine the response of the firms outside the enlarged group, $Y$ to a quantity $X^{\mathcal{G}}$. We have $Y=\frac{n-n_{c}-n_{s}}{n-n_{c}-n_{s}+1}\left(1-X^{\mathcal{G}}\right)$ and $X^{\mathcal{G}}=$ $\operatorname{Max}\left\{\frac{(2-\mu) n_{s}+1-\left[(2-\mu) n_{s}+\mu\right] Y}{(2-\mu) n_{s}+2} ; \frac{n_{s}(1-Y)}{n_{s}+1}\right\}$ where $\mu=\frac{n-n_{c}+\rho}{n-n_{c}}$.
} 


\subsection{Welfare effects of partial acquisitions}

Starting from an initial situation characterized by $\alpha_{s}, \alpha_{c}$ and $n_{c}$, we now examine the consequences of an increase in one of A's stakes (say $\alpha_{2}$ in firm 2) on the equilibrium profits of the whole industry (and welfare), of the "greater" group $\mathcal{G}$ of firms in which A has a positive stake, and of group $\mathcal{C}$ of firms controlled by $\mathrm{A}$.

\section{Are partial acquisitions anticompetitive?}

From Proposition 1, it is clear ${ }^{20}$ that an increase in a controlling share (say $\left.\alpha_{2}\right)$ does not change the equilibrium as long as it remains below the highest controlling share $\left(\alpha_{2} \leq \alpha_{c}\right)$, and simply results in a continuous decrease in $\rho$ when it becomes the highest controlling share. Thus, any partial acquisition that increases a toehold in an already controlled company benefits (or at least does not harm) consumers: the larger the controlling shareholder, the higher the welfare; this is due to a reverse "silent" effect: his controlling stake becoming relatively higher than his outside interests, A becomes more aggressive since the negative impact on silent stakes counts less relatively.

On the contrary, as a silent share (say $\alpha_{2}$ ) goes up while remaining silent, $\rho$ increases continuously. Therefore any silent partial acquisition is harmful for consumers: as seen before, a higher silent stake (say $\alpha_{2}$ ) encourages the acquirer (say shareholder A) to restrict the production in the companies he controls to protect the value of his higher outside interests (the "silent" effect).

Finally, the overall effect of a partial acquisition which turns a silent toehold into a controlling stake is a priori ambiguous. Indeed, as $\alpha_{2}$ keeps increasing, it eventually reaches the control threshold $\frac{\beta_{2}}{2}$; at this level, $\rho$ drops from $\frac{\alpha_{s}+\frac{\beta_{2}}{2}}{\alpha_{c}}$ to $\frac{\alpha_{s}}{\operatorname{Max}\left(\alpha_{c}, \frac{\beta_{2}}{2}\right)}$ and the number of controlled firms goes up from $n_{c}$ to $n_{c}+1$. The simultaneous decrease in $\rho$ and increase in the number of firms under A's control affect total production (and welfare) in opposite directions. However, calculation shows that it actually drops. Acquiring control of a new company leads A to shut an additional firm; this direct effect outweighs the simultaneous indirect effect (higher production of the active controlled firm following the decrease in outside

\footnotetext{
${ }^{20}$ The quantity produced by the entire industry $\left(X^{i n d}\right)$, and therefore welfare, is a decreasing function of $n_{c}$ and $\rho$. In our Cournot model with a constant unit cost, a restriction of the total supply results in an increase in the profit of the whole industry and a decrease in total welfare.
} 
interests). Overall, increasing the number of firms under the control of $\mathrm{A}$ is always anticompetitive. Moreover, although production (and welfare) increase as the share in the newly controlled company gets larger, it never reaches the level prevailing before the acquisition of

control: the highest possible silent stake in firm 2 (close to $\frac{\beta_{2}}{2}$ ) is always less harmful than the highest controlling share $\left(\alpha_{2}=1\right)$.

Figure 3 illustrates how industry output (or welfare) varies with the toehold $\alpha_{2}$ held by A in firm 2, keeping other stakes constant.

\section{Insert Figure 3.}

\section{Who gains, who loses?}

Obviously, silent partial acquisitions always benefit non controlled companies whereas group $\mathcal{C}$ loses (as well as the greater group $\mathcal{G}$ if the number $n_{s}$ of companies in which $\mathrm{A}$ has a silent interest is small enough). The reverse is true for operations which increase already controlling shares. As a consequence, partial acquisitions which do not change $n_{c}$ however lead to a production restructuring and a reallocation of production and profits within the greater group.

Controlling acquisitions also clearly benefit companies that remain out of the control of A. The production and profit of the group of $\left(n_{c}+1\right)$ firms under A's control is however always lower than the sum of the output of the $n_{c}$ firms initially controlled by $\mathrm{A}$ and the output of the newly controlled firm before the acquisition (the price increase is outweighed by the quantity decrease). Therefore, the profits of the group of firms involved in partial acquisitions generally decrease.

However, A may gain from these operations for two reasons. First, the profitability of the acquisition depends on the price paid for the toehold. Second, A's wealth $\left(\sum_{i} \alpha_{i} \Pi_{i}\right)$ is not proportional to the profit of the group $\left(\sum_{i} \Pi_{i}\right)$. When the toeholds are asymmetric, shareholder A may well become wealthier whereas the total profit of the firms in which he has a stake decreases. For example, if group $\mathcal{C}$ loses while rivals (including firms in which $\mathrm{A}$ has a silent interest) gain, the loss incurred by $\mathrm{A}$ in $\mathcal{C}$ may be more than compensated by the increase in the value of his silent stakes (for $\alpha_{c}<\alpha_{s}$ ). The next section examines these questions. 


\section{The acquisition game}

In this section, we study the first stage of the global game in which shareholder A may acquire a share of the equity of firm 2 . We showed in the previous section that the strategic choices of output in the second stage depend on the level of the toehold acquired and its nature, controlling or silent.

In practice, there exist multiple ways to acquire a share or the entire equity of a firm: private negotiation, snapping up shares on the stock market, block trades, tender offers, etc...

We explore two hypotheses under a "take it or leave it" offer. However the results obtained are also valid in the case where shareholders A and B negotiate at the first stage a block sale (see Charléty, Fagart and Souam, 2003). The optimal acquisition policy would be the same. The only difference lies in the sharing of the surplus between the two large shareholders.

In the first sub-section, shareholder A makes a "take it or leave it" block offer to B. In this case, A acquires a stake in 2 directly. Since he controls firm 1's productive and financial decisions, its M\&A policy in particular, A may have firm 1 acquire a share of equity in firm 2. This case of an indirect acquisition is studied in the second sub-section in which firm 1 (rather than shareholder A) makes a "take it or leave it" block offer to B. At this stage of the analysis, there is no reason why these two modes of acquisition should be equivalent. $A$ priori neither dominates from A's point of view.

\subsection{Shareholder A makes a direct block offer to B}

Let us suppose that shareholder A makes a block offer (quantity, price) to the dominant shareholder of 2, namely B, who accepts or rejects it. Proposition 2 describes the equilibrium.

Proposition 2 The optimal share $\alpha_{2}^{*}$ maximizes the joint wealth of $A$ and $B$. Depending on the size of B's controlling block $\beta_{2}$, three outcomes are possible: no acquisition takes place; acquisitions occur and benefit the acquirer's shareholders; acquisitions occur and benefit the target's shareholders. More precisely:

- zone $I\left(\beta_{2} \leq \beta_{I}\right)$ : A acquires a controlling share in firm 2 with any $\left.\left.\alpha_{2}^{*} \in\right] \frac{\beta_{2}}{2}, \beta_{2}\right]$ (acquisitions benefit the acquirer's shareholders); 
- zone II $\left(\beta_{I}<\beta_{2} \leq \beta_{I I}\right)$ : A acquires no share in firm $2\left(\alpha_{2}^{*}=0\right)$ when his silent interest $\alpha_{s}$ is small, and is indifferent between any share $\left[0, \frac{\beta_{2}}{2}\right]$ when it is high (no acquisition or acquisitions that benefit target's shareholders);

- zone III $\left(\beta_{I I}<\beta_{2} \leq \beta_{I I I}\right):$ A acquires a silent interest in firm $2, \alpha_{2}^{*}=2 \beta_{2}+\alpha_{s}-\alpha_{c}\left(n-n_{c}\right)$ (acquisitions benefit target's shareholders);

- zone IV $\left(\beta_{I I I}<\beta_{2}\right)$ : any silent interest $\alpha_{2}^{*} \in\left[\alpha_{c}-\alpha_{s}, \frac{\beta_{2}}{2}\right]$ in firm 2 is an equilibrium when $\alpha_{s}>0$. A is indifferent between acquiring a controlling or a silent interest in firm 2 when $\alpha_{s}=0$ and $\alpha_{2}^{*} \in\left[\alpha_{c}, \beta_{2}\right]$ (acquisitions benefit target's shareholders).

The values taken by the three thresholds $\beta_{I}, \beta_{I I}$ and $\beta_{I I I}$ are given by the following equations:

$$
\begin{gathered}
\beta_{I}=\operatorname{Max}\left(\alpha_{c}, \alpha_{s}\right) \frac{2\left(n-n_{c}+1-\frac{\alpha_{s}}{\operatorname{Max}\left(\alpha_{c}, \alpha_{s}\right)}\right)+1}{\left[n-n_{c}+1-\frac{\alpha_{s}}{\operatorname{Max}\left(\alpha_{c}, \alpha_{s}\right)}\right]^{2}} \\
\beta_{I I}=\alpha_{c} \frac{\left[n-n_{c}-\frac{\alpha_{s}}{\alpha_{c}}\right]}{2} \text { when } \alpha_{s} \leq \alpha_{c} \text { and } \beta_{I I}=1 \text { otherwise. } \\
\beta_{I I I}=\alpha_{c} \frac{\left[n-n_{c}+1-\frac{2 \alpha_{s}}{\alpha_{c}}\right]}{2} \text { when } \alpha_{s} \leq \alpha_{c} \text { and } \beta_{I I I}=1 \text { otherwise. }
\end{gathered}
$$

Figure 4 presents the different zones as a function of $\beta_{2}$ and $\alpha_{s}$ for a given value of $\alpha_{c}$.

\section{Insert Figure 4.}

As already suggested at the end of the third section, the decision criterion for an acquisition is not the sum of the profits of firms 1 and 2 involved in the operation, but the joint profit of shareholders A and B. Thus, even though the joint profit of 1 and 2 combined always decreases, A and B joint wealth may increase when their respective controlling shares are not "too close". As long as the joint wealth of A and B increases following the acquisition (possibly at the expense of other shareholders), A and B are able to share this gain in this game where other shareholders play no role.

Remembering that among the firms in which A holds a controlling stake, only the firm in which A has the highest interest may remain active in equilibrium (due to the "favorite" and the "Hara Kiri" effects), we look more closely at the equilibrium depending on the relative size of $\alpha_{s}$. 
Small silent interest $\left(\alpha_{c} \geq \alpha_{s} \geq 0\right.$, i.e. $\left.\rho \leq 1\right)$

Let us begin with the case where A has a small initial silent interest in firms outside of 1 and 2 .

- In zone I, as $\beta_{2}$ is small relatively to $\alpha_{c}$, in order to maximize the joint wealth of $\mathrm{A}$ and $\mathrm{B}$, firm 2 should be closed, the increase in the value of the stake in 1 far outweighing the decrease in the value of the stake in 2. Therefore, A buys enough equity in 2 to get its control $^{21}$ and favors firm 1 afterwards. This also benefits his silent stakes. The "favorite" effect plays in favor of the previously controlled firm with the highest interest (firm 1) whose shareholders gain.

- In zone II, no acquisition takes place: the weights of A and B in their original firms are too close, and $\alpha_{s}$ too small, to make any acquisition profitable. Indeed, the joint wealth of A and B is closely related to the sum of the profits of firms 1 and 2, which would decrease following the acquisition.

- Zones III and IV correspond to acquisitions leading to an increase in firm 2's profit at the expense of the minority shareholders of the firms initially controlled by A.

In zone III, A acquires a silent interest in firm $2, \beta_{2}$ is greater than $\alpha_{c}$, but not enough to make it profitable for A to close firm 1 (both firms keep a distinct control and positive productions, the "silent" effect is at play).

In zone IV where $\beta_{2}$ is high enough, maximizing $\mathrm{A}$ and $\mathrm{B}$ joint wealth implies closing firm 1. Thus A acquires a sufficiently high interest in firm 2 and stops production in all the previously controlled firms; the "Hara Kiri" effect is at play. When $\alpha_{s}=0$, he is actually indifferent between controlling firm 2 or not. In fact, when A controls firm 2, he maximizes its value exactly as B would if he remained the controlling shareholder. Their interests are completely aligned. When $\alpha_{s}>0$, A is no longer indifferent between acquiring a controlling or a silent stake in firm 2. Indeed, when A controls firm 2, he takes into account the negative impact of firm 2's output on the value of his silent interests, and therefore chooses a level of production for firm 2 that is lower than what would prevail under B's control. As a consequence, when $\beta_{2}$ is high, the overall wealth of $\mathrm{A}$ and $\mathrm{B}$ would actually be smaller under A's control rather than B's. Acquiring a silent share is a commitment not to decrease 2's value afterwards, which explains the rather counter-intuitive result that silent acquisitions

\footnotetext{
${ }^{21}$ In the production game, the number of firms controlled by A increases by one $\left(n_{c}\right.$ is replaced by $\left.\left(n_{c}+1\right)\right)$.
} 
dominate.

\section{High silent interest $\left(\alpha_{s}>\alpha_{c}\right.$, i.e. $\left.\rho>1\right)$}

In this case, since A's silent interest is high compared with his highest initial controlling share $\left(\alpha_{1}=\alpha_{c}\right)$, the output of 1 is initially null in order to favor competitors in which he has a high stake. A silent acquisition in firm 2 would of course not affect this equilibrium in the real sector $\left(\alpha_{s}\right.$ would become even higher). Therefore, no silent partial acquisition possibly increases the joint wealth of A and B. Since A acquires shares at a price which reflects the initial value of firm 2 in our take-it or leave-it game, and nothing really changes after a silent acquisition, A is obviously indifferent between acquiring a silent interest or nothing.

On the other hand, when A takes the control of firm 2, he considers the impact of 2's production level on competitors in which he holds silent interests and reduces the production of 2. A controlling acquisition in firm 2 thus reduces the value of firm 2 and increases the value of competitors. This dilution of 2 is profitable, from the point of view of $\mathrm{A}$ and $\mathrm{B}$ together, only when $\beta_{2}$ is low enough (zone I). This explains why we only have two zones depending on the value of $\beta_{2}$ as illustrated by Figure $4 .^{22}$

\section{Prices, block premia and minority shareholders' wealth}

In this take-it or leave-it framework, the level of the offer (when it exists) made by A is such that it leaves B's wealth unchanged. ${ }^{23}$ Therefore, when the acquisition leads to a decrease in 2's profits (zone I), the price paid for each share acquired by A must include a premium compared with the initial price in order to compensate B for the lower value of his remaining holdings post acquisition. On the other hand, when the acquisition leads to an increase in 2's value, the price actually displays a discount compared with the previously prevailing price, since $\mathrm{B}$ benefits from the increased value of his remaining holdings post acquisition. Of course, in the case where $\mathrm{A}$ acquires the entire block $\beta_{2}$, there is no premium

\footnotetext{
${ }^{22}$ The fact that firm 1 which initially produces nothing is active on the market for corporate control may seem strange; however the extreme result concerning the output is once again due to the linearity of the model; another interpretation is that firm 1 is as an "empty shell" serving shareholder A's interests.

${ }^{23}$ In equilibrium, $\alpha_{2}^{*} p\left(\alpha_{2}^{*}\right)+\left(1-\alpha_{2}^{*}\right) \Pi_{2}^{* \text { post acquisition }}=\beta_{2} \Pi_{2}^{* \text { before acquisition }}$. In a negotiation game, the same acquisitions would occur but the increase in A and B joint wealth would be shared between them (Charléty, Fagart and Souam, 2003).
} 
or discount. ${ }^{24}$

Whereas partial acquisitions always benefit A and B, they always harm minority shareholders of either firm 1 or firm 2. As already noticed, they benefit shareholders from other companies. The asymmetry of the weights of A and B in their original firms is crucial for partial acquisitions to be (privately) profitable.

\section{The incentive to acquire partial interests and the role of initial toeholds}

The incentive to acquire a toehold obviously depend of the total number of firms in the industry: the fiercer is competition in this model $\grave{a}$ la Cournot, the less frequent are acquisitions (the size of zone II increases with the number of firms in the industry). As increasing the number $n_{c}$ of firms controlled by A (leaving $\alpha_{c}$ unchanged) is equivalent to closing one firm, more control in this sense not only reduces competition and welfare, but also enhances the incentives to make further acquisitions.

More control can as well be interpreted as an increase in the controlling toehold. For small values of $\alpha_{c}\left(\alpha_{c}<\alpha_{s}\right.$, which corresponds to a high silent interest), no firm belonging to group $\mathcal{C}$ produces in equilibrium. Thus a small increase in $\alpha_{c}$, as long as the silent interest remains high, plays no role in either the production or the acquisition policy $\left(\beta_{I}\right.$ is independent of $\alpha_{c}$ and there are only two zones). For higher values of $\alpha_{c}\left(\alpha_{c} \geq \alpha_{s}\right.$, which corresponds to a small silent interest), $\beta_{I}, \beta_{I I}$ and $\beta_{I I I}$ increase with $\alpha_{c}$. As the controlling interest gets larger, zone I (target value decreasing acquisitions) increases and zones III and IV (acquirer's value decreasing acquisitions) shrink. In zone I, shareholder A acquires the control of firm 2 and favors firm 1 afterwards. Therefore, the larger shareholder A, the more profitable the acquisition for him, and the higher the incentive to acquire. On the other hand, in zones III and IV where $\alpha_{c}$ is relatively small w.r.t $\beta_{2}$, the acquisition favors firm 2 at the expense of 1 . Thus, target value increasing acquisitions are less profitable for $\mathrm{A}$ and occur less frequently when $\alpha_{c}$ increases.

Whereas controlling toeholds have an ambiguous effect on the incentive to make additional partial acquisitions, silent toeholds always encourage them. It can easily be shown that zone I and zones III and IV together (where shareholder A acquires shares in firm 2) are larger when $\alpha_{s}$ increases. Acquisitions are more frequent for firms which already hold

\footnotetext{
${ }^{24}$ Premia would of course be more frequent in a negotiation game and would in particular be present when the whole block $\beta_{2}$ is acquired.
} 
silent interests in rivals; this is obviously due to the fact that being anti-competitive, they always benefit firms outside of these operations. Thus, the higher A's silent interest in rivals, the higher the incentive to acquire new toeholds. ${ }^{25}$

\subsection{Shareholder A makes an indirect block offer to B}

In this sub-section, we study the case of an indirect acquisition ${ }^{26}$ in which firm 1 (rather than shareholder A) makes, under the control of A, a "take it or leave it" block offer to B. In this framework, $\widehat{\alpha}_{2}$ represents the toehold acquired by firm 1 , and $\alpha_{2}$ the share acquired by shareholder A indirectly through his holdings in 1. Proposition 3 states that only zone I (target value decreasing acquisitions) and zone II (no partial acquisition) remain in this context.

Proposition 3 In the indirect acquisition game of shares from the dominant shareholder of firm 2 by firm 1 controlled by $A$ :

- if $\beta_{2} \leq \beta_{I}^{\text {ind }}$ (zone I), any $\left.\left.\widehat{\alpha}_{2}^{*} \in\right] \frac{\beta_{2}}{2}, \beta_{2}\right]$ is an equilibrium, firm 1 acquires the control of firm 2;

- if $\beta_{2}>\beta_{I}^{\text {ind }}$ (zone II), $\widehat{\alpha}_{2}^{*}=0$ (firm 1 acquires no share in firm 2). The threshold $\beta_{I}^{\text {ind }}$ is given by:

$$
\beta_{I}^{\text {ind }}=\operatorname{Max}\left(1, \frac{\alpha_{s}}{\alpha_{c}}\right) \frac{2\left(n-n_{c}+1-\frac{\alpha_{s}}{\operatorname{Max}\left(\alpha_{c}, \alpha_{s}\right)}\right)+1}{\left[n-n_{c}+1-\frac{\alpha_{s}}{\operatorname{Max}\left(\alpha_{c}, \alpha_{s}\right)}\right]^{2}} .
$$

Let as before $\alpha_{c}=\alpha_{1}$. A's final wealth after an indirect acquisition is: $\alpha_{1}\left[\Pi_{1}+\widehat{\alpha}_{2}\left(\Pi_{2}-\right.\right.$ $p)]+\sum_{j>2} \alpha_{j} \Pi_{j}=\alpha_{1} \Pi_{1}+\alpha_{2}\left(\Pi_{2}-p\right)+\sum_{j>2} \alpha_{j} \Pi_{j}$ where share $\alpha_{2}$ of A in 2 is $\alpha_{1} \widehat{\alpha}_{2}$. Therefore, in the production game ( $p$ is a sunk cost), if A controls 2 indirectly, he always shuts it down since his stake in 2 is by construction lower than his holding in $1\left(\alpha_{2}=\alpha_{1} \widehat{\alpha}_{2} \leq \alpha_{1} \beta_{2}<\alpha_{1}\right)$. The "favorite" effect is at play. On the other hand, if A holds (indirectly) $\alpha_{2}$ silent, although $\alpha_{1}>\alpha_{2}$, A restricts the output of firm 1 due to the "silent" effect. ${ }^{27}$

For these reasons, ex ante, it is never profitable for A to acquire a silent interest in 2 indirectly: the loss incurred on his stake in 1 being by construction relatively large compared

\footnotetext{
${ }^{25}$ It can also be shown that the size of the toehold acquired in 2 is non-decreasing in $\alpha_{s}$ in the sense that when $\alpha_{s}$ increases, there always exist a higher new equilibrium $\alpha_{2}^{*}$.

${ }^{26}$ By assumption, the initial toeholds of $\mathrm{A}$ in other firms are owned directly.

${ }^{27}$ This comes directly from Proposition 1.
} 
to the gain made on his indirect share in 2. Only controlling indirect acquisitions which increase firm 1's operating profits possibly occur. ${ }^{28}$

Whereas such indirect partial acquisitions always harm minority shareholders of 2 (shareholder B being indifferent in this take-it-or-leave game), they do not necessarily benefit minority shareholders of firm 1. First, although it is true that firm 1's equilibrium operating profits $\Pi_{1}^{*}$ always increase, firm 1's equilibrium value $\Pi_{1}^{*}-p \widehat{\alpha}_{2}^{*}$ may decrease after the acquisition: firm 1 pays the pre-acquisition value of B's stake which is worth nothing afterwards. If A has no silent interest, A's final wealth is proportional to firm 1's value; acquisitions that benefit A also create value for minority shareholders of firm 1. But when A has silent stakes in rivals, the increase in their value may compensate a loss in the value of A's interest in 1. This is likely to be true when $\alpha_{s}$ is high and $\alpha_{c}=\alpha_{1}$ low. The profitability threshold ${ }^{29} \widehat{\beta}_{I}^{\text {ind }}$ for the minority shareholders of firm 1 is lower than shareholder A's threshold $\beta_{I}^{\text {ind }}$. Therefore, for $\beta_{2} \in\left[\widehat{\beta}_{I}^{\text {ind }}, \beta_{I}^{\text {ind }}\right]$, A initiates controlling partial acquisitions that also expropriate the minority shareholders of firm 1.

Moreover, it can be checked that $\beta_{I}^{\text {ind }}>\beta_{I}$ : controlling indirect partial acquisitions are more likely than controlling direct acquisitions by A. This is of course due to the fact that A pays only a fraction $\alpha_{1}$ of the amount offered to B (and also gets $\alpha_{1}$ of firm 1's operating profits) in indirect operations but receives the total increase in value of his silent stakes as in direct acquisitions. Therefore, indirect acquisitions may dominate for low values of $\beta_{2}$. On the other hand, for high values of $\beta_{2}$, indirect acquisitions are never profitable for A. Direct acquisitions will be preferred by $\mathrm{A}$ in that case.

Finally, the effect of higher controlling initial interests is no more ambiguous, contrary to the case of direct acquisitions: they always discourage further acquisitions. As silent initial toeholds encourage them, they play in opposite directions. This is due to the fact that acquisitions always decrease the target value.

\footnotetext{
${ }^{28}$ Proposition 3 derives from Proposition 2 where $\beta_{2}$ is simply replaced by $\alpha_{1} \beta_{2}$; it is then clear that zones III and IV can never emerge (zones III and IV correspond to values of $\beta_{2}>\alpha_{1}$, which can never hold when $\beta_{2}$ is replaced by $\left.\alpha_{1} \beta_{2}\right)$.

${ }^{29}$ Simple algebra shows that $\widehat{\beta}_{I}^{\text {ind }}=\left(1-\frac{\alpha_{s}}{\operatorname{Max}\left(\alpha_{s}, \alpha_{c}\right)}\right) \frac{2\left(n-n_{c}\right)+3-\frac{2 \alpha_{s}}{\operatorname{Max}\left(\alpha_{c}, \alpha_{s}\right)}}{\left[n-n_{c}+1-\frac{\alpha_{s}}{\operatorname{Max}\left(\alpha_{c}, \alpha_{s}\right)}\right]^{2}}=\operatorname{Max}\left[\alpha_{c}\left(\alpha_{c}-\right.\right.$ $\left.\left.\alpha_{s}\right) ; 0\right] \beta_{I}^{\text {ind }}$. This threshold decreases with $\frac{\alpha_{s}}{\alpha_{c}}$.
} 


\section{Conclusion}

In a standard framework $\grave{a}$ la Cournot, we show that partial acquisitions, both controlling and silent, always lead to a decrease in the overall profit of the companies involved in the transaction, an increase in their competitors' profit and have a negative impact on the consumer surplus. Still, we do obtain equilibria where a large shareholder gains from acquiring a block of shares, silent or controlling, from a shareholder in a rival firm. Moreover, the higher the already existing silent toeholds in rivals, the stronger the incentive to make further anticompetitive acquisitions. We thus provide an economic argument in favor of more scrutinity of partial acquisitions, even passive ones, by the competition authorities.

The result is partly due to the assumption that a blockholder may actually control a firm when the remaining shares are dispersed among atomistic shareholders. In our model, the relative separation of ownership and control gives rise to "favoritism" within the group of firms in which the dominant shareholder has a stake. When choosing the production level of the firms he controls, he "favors" the firm in which he holds the relatively highest share. If, for example, the controlling block in the target is relatively small compared with his initial toeholds in the other companies, he closes the new firm under his control after the acquisition. Such a target value decreasing acquisition implies the payment of a premium to the selling shareholder whereas minority shareholders of the target lose. ${ }^{30}$ On the contrary, the acquisition of a relatively high share in a rival will lead the acquiring shareholder to close his own company at the expense of its minority shareholders and to the benefit of the target. For such operations, the block may be bought at a discount since, if he keeps a stake in the company, the seller will profit from its increase in value. When the acquirer initially holds high silent toeholds in rivals, he may even sacrifice the controlled companies to the benefit of competitors only. Thus, if they are sufficiently large, shareholders generally tends to protect minority shareholders of their company, as already pointed out in other articles. ${ }^{31}$ Another interesting result concerns the choice between a direct acquisition of shares and an indirect acquisition through the controlled company (a stock "pyramid", see Faccio and Lang, 2000).

\footnotetext{
${ }^{30}$ Such cases are often documented in the economic press. For example, in 2002, the spanish group Bami offered a high premium (60\%) to Banco Bilbao Viscaya Argentaria (BBVA) for the controlling block of 23,9\% of Metrovacesa while the value of the equity has fallen after the acquisition by 8,7\% (cf. Les Echos june,12 2002).

${ }^{31}$ See for example Shleifer and Vishny (1986).
} 
In particular, even in the absence of financial constraints, we show that an indirect controlling acquisition may be preferred when the acquirer already owns silent toeholds in rivals and the targeted block is relatively small. On the other hand, relatively large blocks should be acquired directly according to our findings. The initial ownership structure of firms and the presence of initial stakes in rivals, in particular silent ones, therefore play important roles in determining the share of the target acquired, the nature of the toehold (controlling or silent), the type of acquisition (direct or indirect) and its feasibility for the dominant shareholder.

Another implication of our analysis is that in particular, when the share acquired in the target by the dominant shareholder is higher than his toehold in his original firm, the minority shareholders of the latter are expropriated. In most countries, financial markets regulation aims at protecting the interest of target firms' shareholders and overlooks the interest of bidding firms' shareholders. This finding may explain, at least partly, the well documented poor financial performance of acquiring firms in takeovers.

\section{Acknowledgements}

We thank Gérard Ballot, Georges Bresson, Denis Gromb, Armel Jacques, and the participants of JMA 2003, AFFI 2003 and EARIE 2004 conferences, of the seminars ETAPE, University of Paris 2 (ERMES), University of Nancy 2 and University of Paris-Nord for their useful comments. Our research was financially supported by the Institut Caisse des Dépôts pour la Recherche.

\section{References}

[1]Alley, W. (1997), Partial Ownership Arrangements and Collusion in the Automobile Industry, Journal of Industrial Economics, 45, pp. 191-205.

[2]Amunden, E. and L. Bergman (2002), Will Cross-Ownership Re-Establish Market Power in the Nordic Power Market, The Energy Journal, 23, pp. 73-95.

[3]Barclay, M. and C. Holderness (1989), Private benefits from control of public corporations, Journal of Financial Economics, 25, pp. 375-95.

[4]Barclay, M. and C. Holderness (1991), Negotiated Block Trades and Corporate Control, The Journal of Finance, 46 (3), pp. 861-78. 
[5]Barclay, M. and C. Holderness (1992), The law and large block trades, Journal of Law and Economics, 35, pp. 265-94.

[6]Barclay, M., C. Holderness and D. Sheehan (2001), The Block pricing puzzle, SSRN Working Paper 265712.

[7]Bebchuk, L (1994), Efficient and inefficient sales of corporate control, Quarterly Journal of Economics, 109, pp. 957-93.

[8]Becher, D. and J. Swisher (2002), Do Toeholds Matter? An Examination of Initial Ownership in Takeover Contests, Working paper.

[9]Becht, M. and A. Röell (1999), Blockholdings in Europe, An International Comparison, European Economic Review, 43 (4-6), pp. 1049-56.

[10]Becht, M. and C. Mayer (2002), Corporate Control in Europe, Revue d'Economie Politique, 112 (4), pp. 471-98.

[11]Betton, S. and E. Eckbo (2000), Toeholds, Bid Jumps, and Expected Payoffs in Takeovers, Review of Financial Studies, 13 (4), pp. 841-82.

[12]Bolton, P. and E.L. von Thadden (1998), Liquidity, and Control: A Dynamic Theory of Corporate Ownership", Journal of Institutional and Theoretical Economics, 154 (1), pp. 177-211.

[13]Brander, J. and T. Lewis (1986), Oligopoly and financial structure: The limited liability Effect, American Economic Review, 76 (5), pp. 956-70.

[14]Bresnahan, T. and S. Salop (1986), Quantifying the competitive effects of production joint ventures, International Journal of Industrial Organization, 4, pp. 155-75.

[15]Bris, A. (2002), Toeholds, takeover premium, and the probability of being acquired, Journal of Corporate Finance, 8, pp. 227-53.

[16]Bulow, J., M. Huang and P. Klemperer (1999), Toeholds and Takeovers, Journal of Political Economy, 107 (3), pp. 427-54.

[17]Burkart, M., D. Gromb and F. Panunzi (1997), Large Shareholders, Monitoring, and the Value of the Firm, Quarterly Journal of Economics, 112 (3), pp. 693-728. 
[18]Burkart, M., D. Gromb and F. Panunzi (2000), Agency Conflicts in Public and Negotiated Transfers of Corporate Control, Journal of Finance, 55 (2), pp. 647-77.

[19]Campos, J. and G. Vega (2003), Concentration Measurement Under Cross-ownership: The Case of the Spanish Electricity Sector, Journal of Industry, Competition and Trade, pp. 313-35.

[20]Charléty, P., M.C Fagart and S. Souam (2003), Prises de participations et expropriation des actionnaires minoritaires, Finance, 24 (1), pp. 63-92.

[21]Chowdhry, B. and N. Jegadeesh (1994), Pre-Tender Offer Share Acquisition Strategy in Takeovers, The Journal of Financial and Quantitative Analysis, 29 (1), pp. 117-129.

[22]Dahya, J., O. Dimitrov and J. McConnell (2006), Dominant Shareholders, Corporate Boards and Corporate Value: A Cross-Country Analysis, mimeo Purdue University.

[23]Dasgupta, S. and T. Zhigang (2000), Bargaining, Bonding, and Partial Ownership, International Economic Review, 41 (3), pp. 609-35.

[24]Deneckere, R. and C. Davidson (1985), Incentives to Form Coalitions with Bertrand Competition, RAND Journal of Economics, 16 (4), pp. 473-86.

[25]Dietzenbacher, E., B. Smid and B. Volkerink (2000), Horizontal Integration in the Dutch Financial Sector, International Journal of Industrial Organization, 18, pp. 1223-42.

[26]Dubrow, J. (2001), Challenging the economic incentives analysis of competitive effects in acquisitions of passive minority equity interests, Antitrust Law Journal, 69 (1), pp. 113-145.

[27]Faccio, M. and L. Lang (2000), The Separation of Ownership and Control: an Analysis of Ultimate Ownership in Western European Corporations, Chinese University of Hong Kong mimeo.

[28]Farrell, J. and C. Shapiro (1990), Asset Ownership and Market Structure in Oligopoly, RAND Journal of Economics, 21 (2), pp. 275-92.

[29]Flath, D. (1989), Vertical integration by means of shareholding interlocks, International Journal of Industrial Organization, 7, pp. 369-80. 
[30]Flath, D. (1991), When is it rational for firms to acquire silent interests in rivals?, International Journal of Industrial Organization, 9, pp. 573-583.

[31]Fudenberg, D. and J. Tirole (1984), The Fat-Cat Effect, the Puppy-Dog Ploy, and the Lean and Hungry Look, American Economic Review, 74 (2), pp. 361-66.

[32] Gilo, D. (2000), The Anticompetitive Effect of Passive Investment, Michigan Law Review, 99 (1), pp. 1-47.

[33]Gilo, D., Y. Moshe and Y. Spiegel (2006), Partial Cross Ownership and Tacit Collusion, RAND Journal of Economics, 37 (1), pp. 81-99.

[34] Grossman, S. and O. Hart (1980), Takeover Bids, The Free Rider Problem and the Theory of the Corporation, Bell Journal of Economics, 11, pp. 42-64.

[35]Grossman, S. and O. Hart (1981), The Allocational Role of Takeover Bids in Situations of Asymmetric Information, The Journal of Finance, Vol. XXXVI, N², pp. 253-70.

[36]Högfeldt, P. and K. Högholm (2000), A law and finance theory of strategic blocking and preemptive bidding in takeovers, Journal of Corporate Finance, 6 (4), pp. 403-25.

[37]Johnson, S., La Porta, R., Lopez-de-Silanes, F. and A. Shleifer (2000), Tunneling, American Economic Review, 90 (2), pp. 22-27.

[38]Kahan, M. (1993), Sales of corporate control, Journal of Law, Economics and Organization, 9 , pp. 368-79.

[39]Malueg, David (1992), Collusive behavior and partial ownership of rivals, International Journal of Industrial Organization, 10, pp. 27-34.

[40]O'Brien, D. and S. Salop (2000), Competitive effects of partial ownership: financial interest and corporate control, Antitrust Law Journal, 67, pp. 559-614.

[41]Parker, P. and L.H. Röller (1997), Collusive conduct in duopolies: multi-market contact and cross-ownership in the mobile telephone industry, RAND Journal of Economics, 28 (2), pp. 304-322.

[42]Perry, M. and R. Porter (1985), Oligopoly and the Incentive for Horizontal Merger, American Economic Review, 75 (1), pp. 219-27. 
[43]Reitman, D. (1994), Partial Ownership arrangements and the potential for collusion, Journal of Industrial Economics, Vol. XLII, N³, pp. 313-22.

[44]Reynolds, R. and B. Snapp (1986), The competitive effects of partial equity interests and joint ventures, International Journal of Industrial Organization, 4, pp. 141-53.

[45]Salant, S., Switzer, S. and R. Reynolds (1983), Losses from Horizontal Merger: The Effects of an Exogenous Change in Industry Structure on Cournot-Nash Equilibrium, Quarterly Journal of Economics, 98 (2), pp. 185-99.

[46]Shleifer, A. and R. Vishny (1986), Large Shareholders and Corporate Control, Journal of Political Economy, 94 (3), pp. 461-88.

[47]Singh, R. (1998), Takeover Bidding with Toeholds: The Case of the Owner's Curse, Review of Financial Studies, 11 (4), pp. 679-704.

\section{Appendix}

\subsection{Proof of proposition 1}

We look for the Cournot-Nash equilibrium of the production game between firms outside of A's control and group $\mathcal{C}$ of firms under A's control.

(i) Any independent firm $k \notin \mathcal{C}$ simply maximizes its profit given by:

$$
\left(1-\sum_{i=1}^{n} X_{i}\right) X_{k}
$$

Thus its best response quantity is:

$$
X_{k}=\frac{\operatorname{Max}\left(1-\sum_{i=1, i \neq k}^{n} X_{i}, 0\right)}{2} .
$$

Let $X=\sum_{i \in \mathcal{C}} X_{i}$, represent the total quantity produced by the firms controlled by A and define $\widehat{X}=\sum_{i \notin \mathcal{C}} X_{i}$ the total quantity produced by the firms outside group $\mathcal{C}$ of firms controlled by A. Equation (10) can be rewritten as follows:

$$
2 X_{k}=\operatorname{Max}\left(1-X-\widehat{X}+X_{k}, 0\right), k \notin \mathcal{C} .
$$


For $X$ given, since all independent firms respond in the same way, by symmetry we can write:

$$
X_{k}=\frac{\widehat{X}}{n-n_{c}}=\frac{1-X}{n+1-n_{c}} .
$$

(ii) We now determine the behavior of group $\mathcal{C}$. A's wealth can be written as:

$$
\left(1-\sum_{i=1}^{n} X_{i}\right)\left(\sum_{j=1}^{n} \alpha_{j} X_{j}\right)
$$

For $j \in \mathcal{C}$, A chooses the production $X_{j}$ of firm $j$ and $X=\sum_{j \in \mathcal{C}} X_{j}$ in order to maximize his wealth:

$$
(1-X-\widehat{X})\left(\sum_{j \in \mathcal{C}} \alpha_{j} X_{j}+\sum_{i \notin \mathcal{C}} \alpha_{i} X_{i}\right)
$$

Given $X$, A's wealth is maximized for $X_{j}=0$ when $\alpha_{j}<\operatorname{Max}\left(\alpha_{i}, i \in \mathcal{C}\right) \equiv \alpha_{c}$ and $\sum_{j \in \mathcal{C}} X_{j}=X$. It can then be rewritten as $(1-X-\widehat{X})\left(\alpha_{c} X+\frac{\sum_{i \notin \mathcal{C}} \alpha_{i}}{n-n_{c}} \widehat{X}\right)=\alpha_{c}(1-X-$ $\widehat{X})\left(X+\frac{\rho}{n-n_{c}} \widehat{X}\right)$ where $\rho=\frac{\sum_{i \notin \mathcal{C}} \alpha_{i}}{\alpha_{c}}$.

The best response of shareholder $\mathrm{A}$ is thus $2 X=\operatorname{Max}\left(1-\frac{n-n_{c}+\rho}{n-n_{c}} \widehat{X}, 0\right)$.

(iii) Finally, equilibrium quantities are given by:

$$
\begin{gathered}
X=\frac{1-\rho}{n-n_{c}+2-\rho} \text { and } \widehat{X}=\frac{n-n_{c}}{n-n_{c}+2-\rho} \text { when } \rho \leq 1 \\
X=0 \text { and } \widehat{X}=\frac{n-n_{c}}{n-n_{c}+1} \text { when } \rho>1 .
\end{gathered}
$$

The equilibrium price is then given by $p^{e}=\frac{1}{n-n_{c}+1+\operatorname{Max}(1-\rho, 0)}$ and A's wealth is $\alpha_{c} \frac{\operatorname{Max}(1-\rho, 0)+\rho}{\left[n-n_{c}+1+\operatorname{Max}(1-\rho, 0)\right]^{2}}$.

\subsection{Proof of proposition 2}

Assume that A makes a block offer $\left(p, \alpha_{2}\right)$ to $\mathrm{B}$. If $\mathrm{B}$ rejects this offer, his wealth is $\beta_{2} \Pi_{2}^{*}\left(\alpha_{1}, 0, \ldots, \alpha_{n}\right)$. If he accepts, he gets $\left(\beta_{2}-\alpha_{2}\right) \Pi_{2}^{*}\left(\alpha_{1}, \alpha_{2}, \ldots, \alpha_{n}\right)+\alpha_{2} p$. He will therefore accept provided that the proposed price is such that $\left(\beta_{2}-\alpha_{2}\right) \Pi_{2}^{*}\left(\alpha_{1}, \alpha_{2}, \ldots, \alpha_{n}\right)+\alpha_{2} p \geq$ $\beta_{2} \Pi_{2}^{*}\left(\alpha_{1}, 0, \ldots, \alpha_{n}\right)$. Anticipating this behavior, A offers the smallest price compatible with this condition, such that his participation constraint is binding. Shareholder A's wealth is 
then given by:

$$
\begin{aligned}
& \sum_{i \neq 2} \alpha_{i} \Pi_{i}^{*}\left(\alpha_{1}, \alpha_{2}, \ldots, \alpha_{n}\right)+\alpha_{2} \Pi_{2}^{*}\left(\alpha_{1}, \alpha_{2}, \ldots, \alpha_{n}\right)-\alpha_{2} p \\
= & \sum_{i \neq 2} \alpha_{i} \Pi_{i}^{*}\left(\alpha_{1}, \alpha_{2}, \ldots, \alpha_{n}\right)+\beta_{2} \Pi_{2}^{*}\left(\alpha_{1}, \alpha_{2}, \ldots, \alpha_{n}\right)-\beta_{2} \Pi_{2}^{*}\left(\alpha_{1}, 0, \ldots, \alpha_{n}\right),
\end{aligned}
$$

and he will propose $\alpha_{2} \in\left[0, \beta_{2}\right]$ which maximizes the above expression. Define $L\left(\alpha_{2}\right)=$ $\sum_{i \neq 2} \alpha_{i} \Pi_{i}^{*}\left(\alpha_{1}, \alpha_{2}, \ldots, \alpha_{n}\right)+\beta_{2} \Pi_{2}^{*}\left(\alpha_{1}, \alpha_{2}, \ldots, \alpha_{n}\right)$. In equilibrium the optimal share $\alpha_{2}$ maximizes $L\left(\alpha_{2}\right)$ in $\left[0, \beta_{2}\right]$ since $\beta_{2} \Pi_{2}^{*}\left(\alpha_{1}, 0, \ldots, \alpha_{n}\right)$ does not depend on $\alpha_{2}$.

\section{The optimum among the controlling interests}

Consider the case where A controls firm 2. As $n_{c}$ denotes the number of firms controlled by $\mathrm{A}$ before the partial acquisition in firm 2, the number of controlled firms becomes $n_{c}+1$. $\alpha_{c}$ is the highest initial controlling share $\left(\alpha_{c}=\operatorname{Max}\left(\alpha_{i}, i \in \mathcal{C}-\{2\}\right)\right.$ and $\alpha_{s}$ the sum of A's silent interests. Thus $\rho=\frac{\alpha_{s}}{\operatorname{Max}\left(\alpha_{c}, \alpha_{2}\right)}$. $L$ can be nicely expressed:

$$
\begin{aligned}
L\left(\alpha_{2}\right) & =\frac{\operatorname{Max}\left(\alpha_{c}, \alpha_{2}, \alpha_{s}\right)+\left(\beta_{2}-\alpha_{2}\right) \lambda \operatorname{Max}(1-\rho, 0)}{\left[n-n_{c}+\operatorname{Max}(1-\rho, 0)\right]^{2}} \\
\text { with } \lambda & =1 \text { if } \alpha_{2}>\alpha_{c} \text { and } \lambda=0 \text { otherwise. }
\end{aligned}
$$

We want to show that the optimal value of $L$ is:

$$
L_{c}^{*}=\frac{\operatorname{Max}\left(\beta_{2}, \alpha_{c}, \alpha_{s}\right)}{\left[n-n_{c}+1-\frac{\alpha_{s}}{\operatorname{Max}\left(\beta_{2}, \alpha_{c}, \alpha_{s}\right)}\right]^{2}} .
$$

(15) obviously holds when $\operatorname{Max}\left(\beta_{2}, \alpha_{c}, \alpha_{s}\right)=\alpha_{c}$ or $\operatorname{Max}\left(\beta_{2}, \alpha_{c}, \alpha_{s}\right)=\alpha_{s}$. Indeed, in these two cases, $L($.$) does not depend on \alpha_{2}$, either because $\lambda=0$ or because $\rho>1$. As a consequence, when $\beta_{2} \leq \operatorname{Max}\left(\alpha_{c}, \alpha_{s}\right)$, the optimal solution $\alpha_{2}^{*}$ is any share in $\left.] \frac{\beta_{2}}{2}, \beta_{2}\right]$. We thus assume in the following that $\beta_{2}>\operatorname{Max}\left(\alpha_{c}, \alpha_{s}\right)$.

When $\alpha_{2} \leq \operatorname{Max}\left(\alpha_{c}, \alpha_{s}\right), L($.$) does not depend on \alpha_{2}$. Conversely, when $\alpha_{2}>\operatorname{Max}\left(\alpha_{c}, \alpha_{s}\right)$, we have $\lambda=1$, and $\rho<1$ so $L$ can be written $\frac{\alpha_{s}+\beta_{2}\left(1-\frac{\alpha_{s}}{\alpha_{2}}\right)}{\left[n-n_{c}+1-\frac{\alpha_{s}}{\alpha_{2}}\right]^{2}}$. L(.) does not depend on $\alpha_{2}$ when $\alpha_{s}=0$. When $\alpha_{s}>0$, the derivative of $L$ with respect to $\alpha_{2}$ has the sign of:

$$
\begin{aligned}
\beta_{2}\left[n-n_{c}+1-\frac{\alpha_{s}}{\alpha_{2}}\right]-2\left[\alpha_{s}+\beta_{2}\left(1-\frac{\alpha_{s}}{\alpha_{2}}\right)\right] & =\beta_{2}\left[n-n_{c}-1+\frac{\alpha_{s}}{\alpha_{2}}\right]-2 \alpha_{s} \\
& \geq \beta_{2}\left[n-n_{c}-1\right]-\alpha_{s} \text { as } \alpha_{2} \leq \beta_{2} .
\end{aligned}
$$

This latter expression is positive since $\beta_{2}>\alpha_{s}$ and $n-n_{c} \geqslant 2$. Hence $L($.$) increases with$ respect to $\alpha_{2}$, and the optimal share, constrained to be higher than $\operatorname{Max}\left(\alpha_{c}, \alpha_{s}\right)$, is $\beta_{2}$. We 
have to prove now that the optimal share is actually not smaller than $\operatorname{Max}\left(\alpha_{c}, \alpha_{s}\right)$ when feasible (that is when $\frac{\beta_{2}}{2}<\operatorname{Max}\left(\alpha_{c}, \alpha_{s}\right)<\beta_{2}$ ). When $\alpha_{s} \geq \alpha_{c}, L($.) is continuous w.r.t. $\alpha_{2}$, so the optimal share is $\beta_{2}$. When conversely $\alpha_{c}>\alpha_{s}, L($.$) is discontinuous at \alpha_{2}=\alpha_{c}$,

equates $L\left(\alpha_{c}\right)=\frac{\alpha_{c}}{\left[n-n_{c}+1-\frac{\alpha_{s}}{\alpha_{c}}\right]^{2}}$ for any $\alpha_{2} \leq \alpha_{c}$. Moreover $L\left(\alpha_{c}^{+}\right)<L\left(\alpha_{c}^{-}\right)$. However, it is easy to show that $L\left(\alpha_{c}\right)$ increases with respect to $\alpha_{c}$ whenever $n-n_{c} \geqslant 2$, so finally $L\left(\alpha_{c}\right) \leq L\left(\beta_{2}\right)$ as $\beta_{2}>\alpha_{c}$.

\section{Comparing controlling and silent acquisitions}

Assume now that A does not control firm 2. Define $\alpha_{s}=\sum_{i \neq 2, i \notin \mathcal{C}} \alpha_{i}$ the sum of the initial silent interests held by shareholder $\mathrm{A}$ in other firms. Thus $\rho=\frac{\alpha_{2}+\alpha_{s}}{\alpha_{c}}$ and $\alpha_{2} \in\left[0, \frac{\beta_{2}}{2}\right]$ so $L\left(\alpha_{2}\right)$ can be written as:

$$
L_{s}\left(\alpha_{2}\right)=\frac{\alpha_{c} \operatorname{Max}\left(1-\frac{\alpha_{2}+\alpha_{s}}{\alpha_{c}}, 0\right)+\beta_{2}+\alpha_{s}}{\left[n-n_{c}+1+\operatorname{Max}\left(1-\frac{\alpha_{2}+\alpha_{s}}{\alpha_{c}}, 0\right)\right]^{2}} .
$$

- As a first step, note that $L_{s}\left(\alpha_{2}\right)$ does not depend on $\alpha_{2}$ in case of high silent interests that is when $\alpha_{s}>\alpha_{c}$. Comparing $L_{s}(0)$ and $L_{c}^{*}$ in that case gives

$$
L_{s}(0)-L_{c}^{*}=\frac{\beta_{2}+\alpha_{s}}{\left[n-n_{c}+1\right]^{2}}-\frac{\operatorname{Max}\left(\beta_{2}, \alpha_{s}\right)}{\left[n-n_{c}+1-\frac{\alpha_{s}}{\operatorname{Max}\left(\beta_{2}, \alpha_{s}\right)}\right]^{2}} .
$$

When $\beta_{2} \leq \alpha_{s}, L_{s}(0)-L_{c}^{*}>0$ if and only if $\beta_{2}>\beta_{I}$. When $\beta_{2}>\alpha_{s}, L_{s}(0)-L_{c}^{*}>0$.

So when $\beta_{2}>\beta_{I}$ (i.e. in zone II for high silent interest), A prefers acquiring any silent interest to a controlling one.

- In case of small silent interests (i.e. when $\alpha_{c}>\alpha_{s}$ ), $L_{s}($.$) is a continuous function of$ $\alpha_{2}$. Taking the derivative of $L_{s}\left(\alpha_{2}\right)$ w.r.t. $\alpha_{2}$ in $\left[0, \alpha_{c}-\alpha_{s}\right]$ shows that $L_{s}$ increases with $\alpha_{2}$ if and only if $\alpha_{2} \leq \alpha_{2}^{*}=2 \beta_{2}+\alpha_{s}-\alpha_{c}\left[n-n_{c}\right]$. When $\alpha_{2}^{*} \leq 0\left(\beta_{2} \leq \beta_{I I}\right)$, the optimal silent interest is thus zero (zones I and II). Conversely, when $0<\alpha_{2}^{*} \leq \alpha_{c}-\alpha_{s}\left(\beta_{I I}<\beta_{2} \leq \beta_{I I I}\right)$ the optimal silent interest is $\alpha_{2}^{*}$ (zone III). Finally, if $\alpha_{2}^{*}>\alpha_{c}-\alpha_{s},\left(\beta_{2}>\beta_{I I I}\right) L_{s}\left(\alpha_{2}\right)$ does not depend on $\alpha_{2}$. A is thus indifferent between any silent share higher than $\alpha_{c}-\alpha_{s}$ (zone IV).

- Let us now show that A always prefers controlling in zone I under small silent interests. As a technical point, it is easy to state that the function $f(x)=\frac{x}{\left[n-n_{c}+1-\frac{\alpha_{s}}{x}\right]^{2}}$ increases 
with respect to $x \geqslant \alpha_{s}$ whenever $n-n_{c} \geq 2$. Thus the difference $L_{s}(0)-L_{c}^{*}$ is such that:

$$
L_{s}(0)-L_{c}^{*} \leq \frac{\alpha_{c}+\beta_{2}}{\left[n-n_{c}+2-\frac{\alpha_{s}}{\alpha_{c}}\right]^{2}}-\frac{\alpha_{c}}{\left[n-n_{c}+1-\frac{\alpha_{s}}{\alpha_{c}}\right]^{2}} .
$$

This last expression is negative if $\beta_{2} \leq \beta_{I}$, that is in zone I.

- Finally we have to show that within the zones II, III and IV, A prefers acquiring silent shares rather than controlling ones if $\alpha_{s}>0$.

In zone IV $\beta_{2}>\beta_{I I I}>\alpha_{c}$, a straighforward calculus shows that $L_{s}^{*}-L_{c}^{*}$ increases with $\alpha_{s}$ and equates 0 for $\alpha_{s}=0$ (in this case, $\mathrm{A}$ is indifferent between controlling firm 2 and acquiring a silent interest in it).

Note that whenever $n-n_{c} \geq 3, L_{s}(0)-L_{c}^{*}$ is strictly positive at $\beta_{2}=\alpha_{c}$. Moreover, $L_{s}(0)-L_{c}^{*}$ increases with respect to $\alpha_{c}$ when $\alpha_{c} \leq \beta_{2}<\beta_{I I I}$ so is strictly positive in zones II and III. As a consequence, whenever $\beta_{2} \geq \alpha_{c}, L_{s}\left(\alpha_{2}^{*}\right) \geq L_{s}(0)>L_{c}^{*}$ and the optimal silent interest dominates the optimal controlling one.

Lastly, in zone II when $\beta_{2}<\alpha_{c}$, we have $L_{s}(0)-L_{c}^{*}>0$. Indeed, it is easy to see that $L_{s}(0)-L_{c}^{*}$ increases w.r.t. $\beta_{2}$ and equals zero when $\beta_{2}=\beta_{I}$. So in this case, acquiring a silent interest is better than controlling firm 2 .

\subsection{Proof of proposition 3}

Assume now that shareholder A buys shares through firm 1 in which he has the highest controlling interest. When firm 1 buys $\widehat{\alpha}_{2} \in\left[0, \beta_{2}\right]$ shares from shareholder $\mathrm{B}$, control is obtained when $\widehat{\alpha}_{2}>\frac{\beta_{2}}{2}$. Moreover, for given quantities $X_{1}, X_{2}, \ldots, X_{n}$, the wealths of shareholders A and $\mathrm{B}$ are given by:

$$
\begin{gathered}
W_{A}=\sum_{i \neq 2} \alpha_{i} \Pi_{i}\left(X_{1}, X_{2}, \ldots, X_{n}\right)+\alpha_{c} \widehat{\alpha}_{2}\left\{\Pi_{2}\left(X_{1}, X_{2}, \ldots, X_{n}\right)-p\right\} \\
W_{B}=\left(\beta_{2}-\widehat{\alpha}_{2}\right) \Pi_{2}\left(X_{1}, X_{2}, \ldots, X_{n}\right)+\widehat{\alpha}_{2} p .
\end{gathered}
$$

Recall that A owns $\alpha_{i}$ shares of firm $i$, with $\alpha_{2}=\alpha_{c} \widehat{\alpha}_{2}$ shares of firm 2. Taking into account the equilibrium in the real sector, we obtain:

$$
\begin{gathered}
W_{A}=\sum_{i} \alpha_{i} \Pi_{i}^{*}\left(\alpha_{1}, \alpha_{2}, \alpha_{3}, \ldots, \alpha_{n}\right)-\alpha_{2} p \text { with } \alpha_{2} \leq \alpha_{c} \beta_{2} \\
\text { and } W_{B}=\left(\beta_{2}-\frac{\alpha_{2}}{\alpha_{c}}\right) \Pi_{2}^{*}\left(\alpha_{1}, \alpha_{2}, \alpha_{3}, \ldots, \alpha_{n}\right)+\frac{\alpha_{2}}{\alpha_{c}} p .
\end{gathered}
$$


As in the preceding proof, assume that firm 1 offers to buy $\widehat{\alpha}_{2}=\frac{\alpha_{2}}{\alpha_{c}}$ shares at a price $p$. If $\mathrm{B}$ rejects the offer, he gets $\beta_{2} \Pi_{2}\left(\alpha_{1}, 0, \alpha_{3}, \ldots, \alpha_{n}\right)$. If he accepts it, his wealth becomes $W_{B}$. He therefore accepts the offer if:

$$
\left(\beta_{2}-\frac{\alpha_{2}}{\alpha_{c}}\right) \Pi_{2}^{*}\left(\alpha_{1}, \alpha_{2}, \alpha_{3}, \ldots, \alpha_{n}\right)+\frac{\alpha_{2}}{\alpha_{c}} p \geq \beta_{2} \Pi_{2}^{*}\left(\alpha_{1}, 0, \alpha_{3}, \ldots, \alpha_{n}\right)
$$

Anticipating this behavior, A offers B a pair quantity-price such that his participation constraint is binding, involving a wealth:

$$
\begin{aligned}
W_{A}= & \sum_{i \neq 2} \alpha_{i} \Pi_{i}^{*}\left(\alpha_{1}, \alpha_{2}, \alpha_{3}, \ldots, \alpha_{n}\right)+\beta_{2} \alpha_{c} \Pi_{2}^{*}\left(\alpha_{1}, \alpha_{2}, \alpha_{3}, \ldots, \alpha_{n}\right) \\
& \left.-\beta_{2} \alpha_{c} \Pi_{2}^{*}\left(\alpha_{1}, 0, \alpha_{3}, \ldots, \alpha_{n}\right)\right\} .
\end{aligned}
$$

The optimal share $\alpha_{2} \in\left[0, \alpha_{c} \beta_{2}\right]$ maximizes the above expression. Finally, we obtain the same problem as in proposition 2 , where $\beta_{2}$ is replaced by $\beta_{2} \alpha_{c}$. 


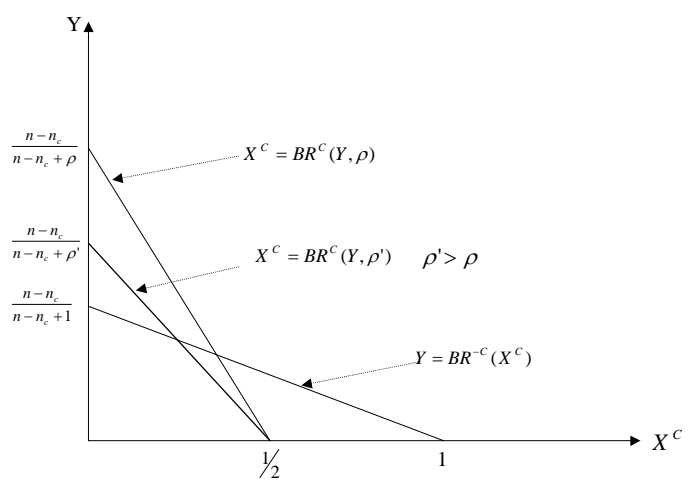

Figure 1: Aggregate best-response curve of group $\mathcal{C}$.

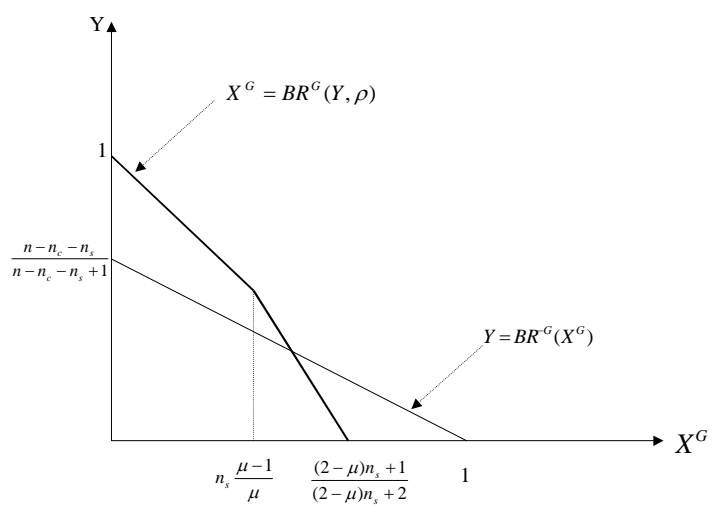

Figure 2: Aggregate best-response curve of group $\mathcal{G}$. 


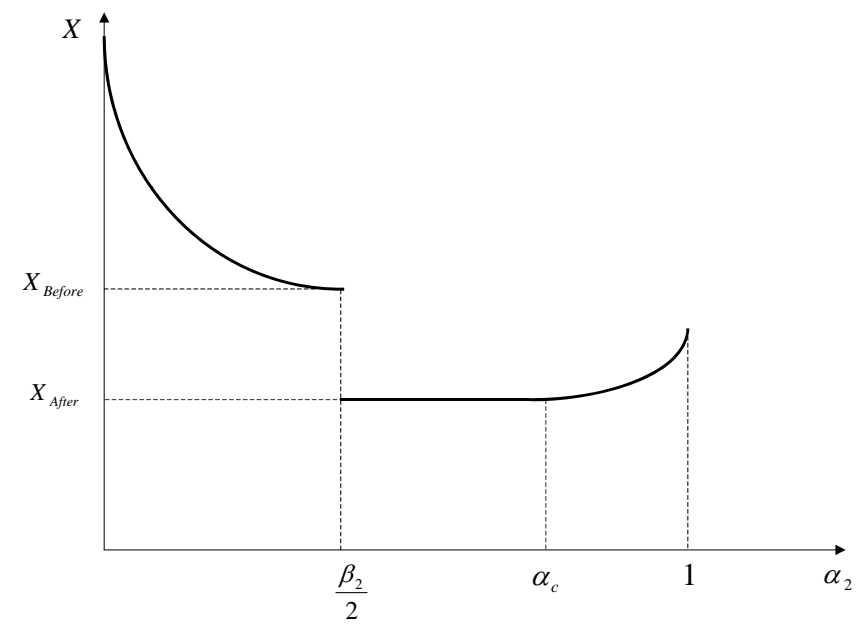

Figure 3: Variation of the total output with the toehold $\alpha_{2}$.

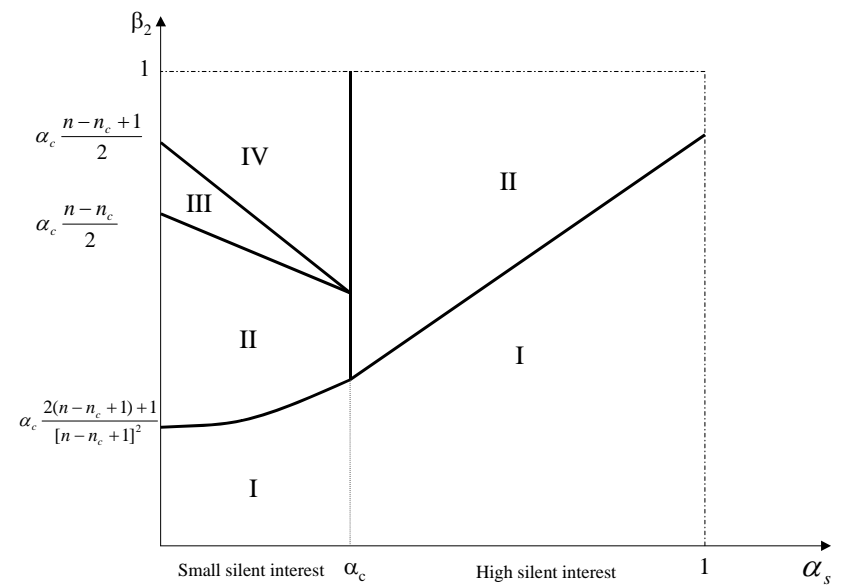

Figure 4: Zones with or without acquisitions. 